\title{
Physician billing data reveal striking gender pay gap
}

Cite as: CMAJ 2020 September 8;192:E1051-2. doi: 10.1503/cmaj.1095894

Posted on cmajnews.com on August 21, 2020

A n Ontario Medical Association (OMA) analysis has found a $15.6 \%$ unexplained pay gap between female and male physicians.

The analysis, based on billings from doctors to the Ontario Health Insurance Plan, accounted for years in practice, specialty, days worked, and other factors to make an "apples-to-apples" comparison.

The pay gap was biggest in family medicine, at $19 \%$, and smallest in surgical specialties, at about $10 \%$. Gender disparities in billings were also more pronounced in semi-urban areas than in urban and rural areas, and among physicians working under fee-for-service versus alternative payment plans.

According to the report, there are many possible reasons for these disparities, including bias in payment models and fee schedules, and discrimination in referrals and career opportunities.

"A lot of it can be explained by the amount of time that female physicians spend with their patients," said OMA President Dr. Samantha Hill. Payment models that reward seeing more patients in less time tend to disadvantage female doctors and may undercut the kind of care that Canadians want, Hill said. "If you talk to patients, we hear patients want to spend more time with their physicians."

Hill noted that female doctors might spend extra time with patients for reasons beyond their control. For example, studies show that patients feel more comfortable asking questions of female doctors versus males.

Meanwhile, doctors may be more likely to refer patients requiring a larger time investment to female colleagues. Hill and other female surgeons at

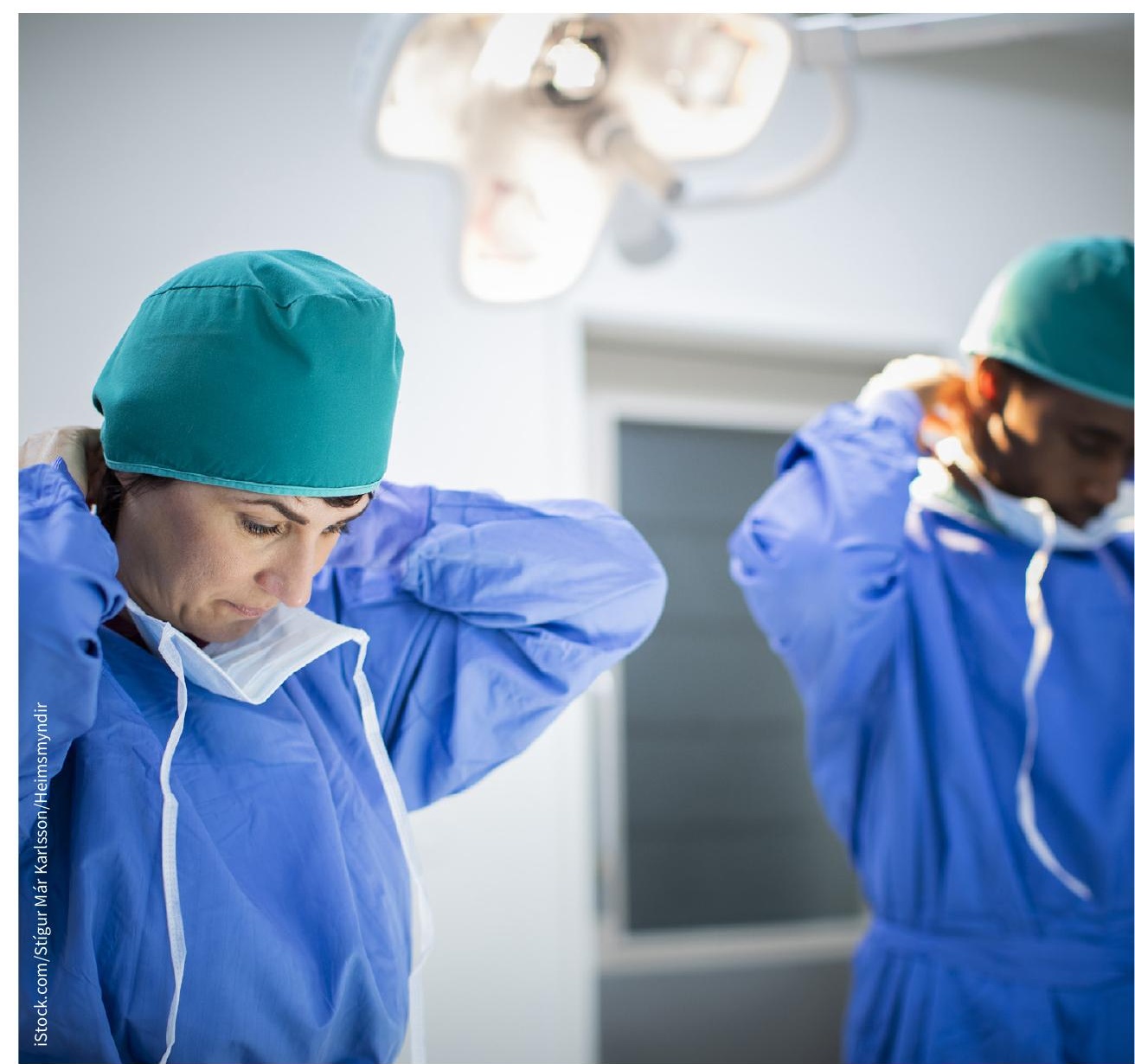

If you're a female doctor in Ontario, you're likely paid less than your male peers.

St. Michael's Hospital in Toronto have noticed that they tend to receive more "soft referrals" to have conversations with patients than their male peers, who get more requests to perform procedures that pay far better.

According to Dr. Clover Hemans, cochair of OMA's committee for women, "both in terms of staff and patient expectations, the patients come to us because they see [us] as being more nurturing."
Female doctors tend to see a higher proportion of female patients, who tend to seek care more often than male patients, Hemans said. For doctors paid based on how many patients they enroll in their practice, those with a higher proportion of female patients often can't take on as many people overall.

Fee schedules also undervalue services predominantly for women, Hemans said. For example, doctors are paid a premium 
for patients with heart disease or diabetes, which are more common in men, but not for patients with anxiety, which is more common in women.

Some fee schedule disparities are more overt; Hemans and Hill noted that draining a vulvar abscess pays about half as much as draining a scrotal abscess, despite the procedures involving similar complexity.

Dr. Sharon Bal, the other co-chair of OMA's committee for women, said the gender pay gap is likely bigger than the data suggest. Their analysis didn't account for additional pay from leadership roles, where men are overrepresented, and it looked only at billings, not take-home pay. When women take parental leave, they may still receive capitation payments, but that money pays for their replacement and overheads, Bal said.

The report calls on the OMA to advocate for reform to payment schedules, more leadership and mentorship opportunities for women, improved parental benefits, and a campaign to improve pay equity within hospitals and medical schools. In addition, Hill said the profession should consider "moving away from a fee-forservice model entirely."

Wendy Glauser, Toronto, Ont. 